\title{
ALTERNATIF PEMECAHAN MASALAH PADA SIMPANG TIGA KARIANGAU - SOEKARNO HATTA KM 5.5, BALIKPAPAN DITINJAU DARI KONDISI GEOMETRIK ${ }^{[1]}$
}

\author{
Budi Hartanto Susilo $^{[2]}$, Apriyanto Loentan ${ }^{[3]}$
}

\begin{abstract}
ABSTRAK
Jalan Soekarno Hatta merupakan Jl. Arteri primer yang menghubungkan Balikpapan-Samarinda sepanjang $115 \mathrm{~km}$. Jalan ini mempunyai beberapa titik rawan kecelakaan diantaranya simpang tiga Kariangau - Soekarno Hatta pada Km. 5.5 dari Balikpapan. Simpang tiga ini berpotensi besar untuk terjadinya kecelakaan karena kondisi geometrik yang jelek dengan kelandaian yang terjal pada jalan minor dan pada salah satu lengan jalan mayor. Rupanya pemasangan lampu lalu lintas tidak memecahkan masalah ini sehingga kenyataan dilapangan lampu ini tidak dioperasikan. Penanganan harian saat ini oleh petugas polantas pada waktu sibuk pagi saja. Perlu perbaikan geometrik dan lajur dengan kanalisasi arus sehingga potensi kecelakaan merging conflict dapat dieliminasi. Hal ini dapat dipahami karena dalam posisi menanjak umumnya pengemudi tancap gas dalam lajurnya dan sulit untuk space sharing dengan kendaraan yang datang dari arah yang berbeda sehingga kondisi ini sering menimbulkan terjadinya merging conflict dengan tingkat kecelakaan luka ringan atau kerusakan kendaraan. Analisa lapangan memberikan solusi perlunya penambahan lajur menerus dan lajur belok kiri serta separator untuk menghindari konflik.
\end{abstract}

Kata kunci : Geometrik simpang, Kanalisasi, Separator, Kecelakaan.

\begin{abstract}
Soekarno-Hatta is an arterial primary road which connecting Balikapapan-Samarinda along $115 \mathrm{~km}$. It has some accident troubled point in between such as Kariangau-Soekarno-Hatta junction at km 5,5 from Balikpapan. This junction is potentially to have an accident it has a worse geometric conditions as shown from critical grade on the minor road and major road. Unfortunately, traffic light - which take a position to controlled this junction - could not handle and solve the problem on this junction. Daily controlled have been done by police officer only on the morning peak hour. So, it should be need repairing geometric and lanes by making a traffic canal to eliminate the accident potential from merging conflict. This reason could be happened cause the drivers will increase vehicle speed on their lanes and it makes difficult to sharing lanes with the vehicle which coming from the other direction. Field analysis give a solution that this junction need additional continous lanes and separator to avoid the conflict.
\end{abstract}

Keywords : Junction geometric, Channelization, Separator, Accident.

\section{PENDAHULUAN}

\subsection{Latar Belakang}

Kota Balikpapan mempunyai peran dan fungsi kota yang sangat penting baik untuk

Kalimantan Timur maupun Kawasan Timur Indonesia yang ditetapkan sebagai Pusat Kegiatan Nasional (PKN). Kota Samarinda adalah ibukota Propinsi Kalimantan Timur yang 
ditetapkan sebagai Pusat Kegiatan Wilayah. Kota Bontang dan Tenggarong ditetapkan sebagai kota penyebar kegiatan ekonomi.

Jalan utama yang menghubungkan kota Balikpapan dengan Kota Samarinda adalah jalan Soekarno Hatta yang merupakan jalan Arteri Primer. Akses utama menuju kota Samarinda ini memiliki beberapa tempat yang disinyalir sering terjadi kecelakaan diantaranya adalah Simpang Kariangau yang berada pada Km 5,5 Balikpapan, yang merupakan pertemuan antara Jalan Soekarno Hatta dengan Jalan Kariangau. Dalam upaya pemecahan masalah pada simpang ini dapat dilakukan dengan 2 metode yaitu pengaturan sinyal (signalized controlled) dan pengaturan tanpa sinyal (unsignalized controlled).

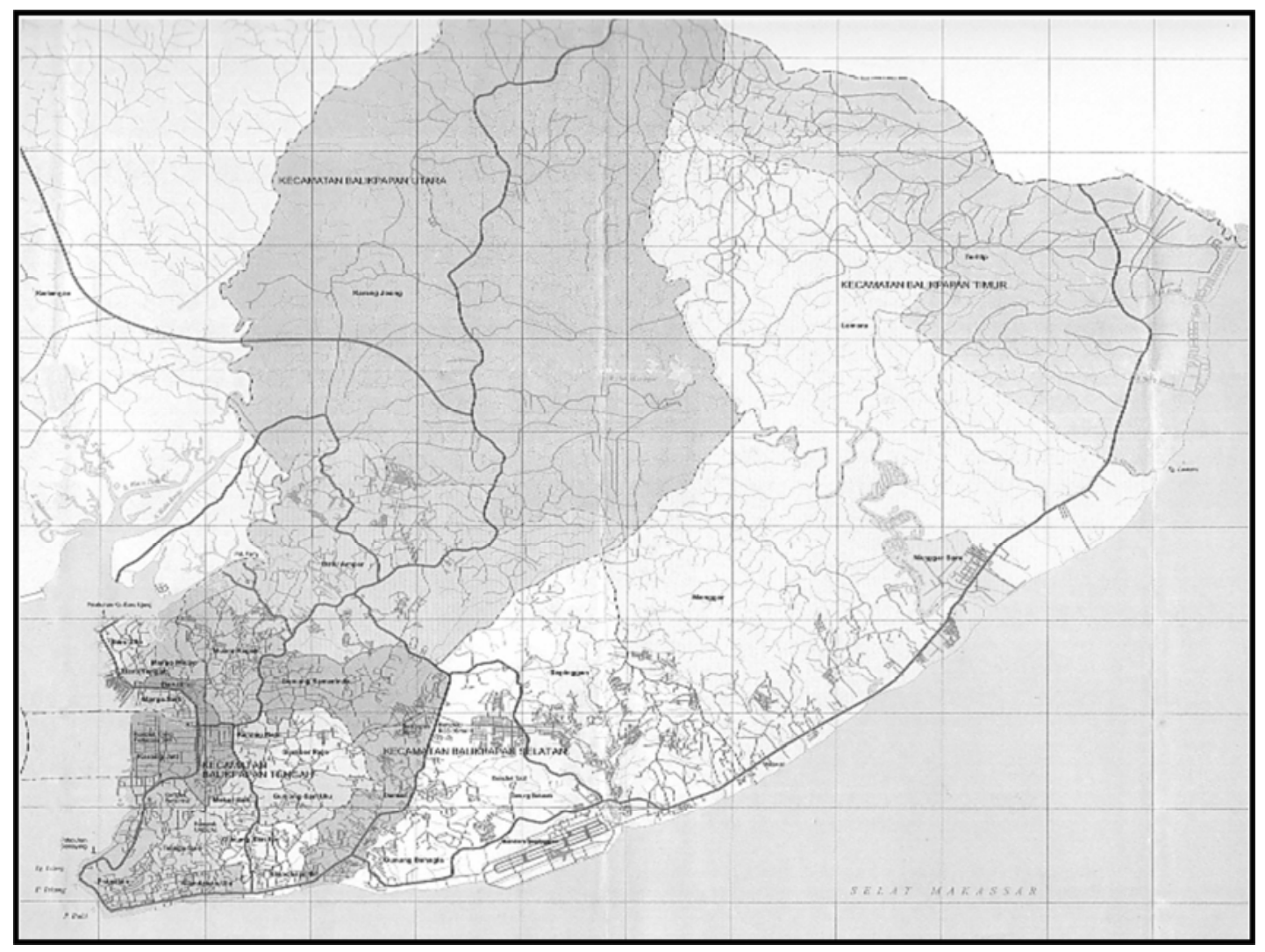

Gambar 1. Peta Lokasi Kegiatan Studi

Untuk pengaturan sinyal dilakukan dengan penghitungan ulang waktu siklus optimum dalam kondisi eksisting, sedangkan untuk pengaturan tanpa sinyal dilakukan dengan rekayasa geometrik yakni penambahan lajur, pembuatan speed trap, pembuatan pulau/separator, serta pengaturan taper. Kedua metode tersebut dapat di aplikasikan salah satu saja ataupun bisa kombinasi keduanya, dan saat ini akan dilakukan kajian terhadap 
salah satu metode diatas yaitu pemecahan masalah persimpangan dengan pengaturan tanpa sinyal yang ditinjau dari kondisi geometriknya.

\subsection{Maksud Dan Tujuan}

Maksud kegiatan studi Peningkatan Kinerja Simpang Soekarno Hatta - Kariangau Km 5,5 Balikpapan adalah untuk mengurangi kecelakaan dan melancarkan lalu lintas di simpang kariangau khususnya pada jalan Soekarno Hatta agar menjadi tertib dan teratur tanpa ada hambatan yang berarti.

Adapun tujuannya adalah melakukan pengaturan kembali Simpang Kariangau berdasarkan perbaikan geometrik dengan kanalisasi dan manajemen pergerakan simpang.

\subsection{Batasan Studi}

Dalam studi ini permasalahan dibatasi hanya pada mencari alternatif pemecahan masalah persimpangan yang dialami oleh simpang kariangau dengan melakukan pengaturan kembali pergerakan kendaraan melalui rekayasa geometrik.

\section{PENGUMPULAN DAN PENGOLAHAN DATA PRIMER}

Untuk mengumpulkan informasi kondisi faktual yang terjadi disekitar simpang kariangau, maka dilakukan beberapa kegiatan survei di sekitar simpang tersebut. Kegiatan ini meliputi :

1. Survei Jaringan Jalan Sekitar Simpang Kariangau

2. Survei Pergerakan Lalu Lintas Simpang Kariangau

3. Survei Geometri Simpang Kariangau

4. Survei Tata Guna Lahan Sekitar Simpang Kariangau

\subsection{Survei Jaringan Jalan Sekitar Simpang Kariangau}

Pada kegiatan survei jaringan jalan yang ada disekitar simpang kariangau, dilakukan identifikasi ruas-ruas jalan yang berpengaruh terhadap kondisi pergerakan lalu lintas di simpang tersebut. Seperti diketahui bahwa simpang kariangau ini merupakan simpang tiga lengan yang terbentuk dari pertemuan antara Jalan Soekarno-Hatta dengan Jalan menuju Kariangau yang bertemu di km 5,5 Kota Balikpapan. Tidak jauh dari simpang ini yaitu \pm 500 m ke arah selatan Jalan Soekarno-Hatta juga terdapat simpang yang dikenal dengan simpang Km.5 Balikpapan. Kondisi simpang yang berdekatan ditambah lagi pergerakan kendaraan yang cukup ramai dijalur ini menjadikan ruas jalan Soekarno-Hatta pada segmen ini rawan 
dengan kecelakaan dan kemacetan. Beberapa kondisi jaringan jalan dan persimpangan yang ada disekitar simpang dapat dilihat pada Gambar 2.

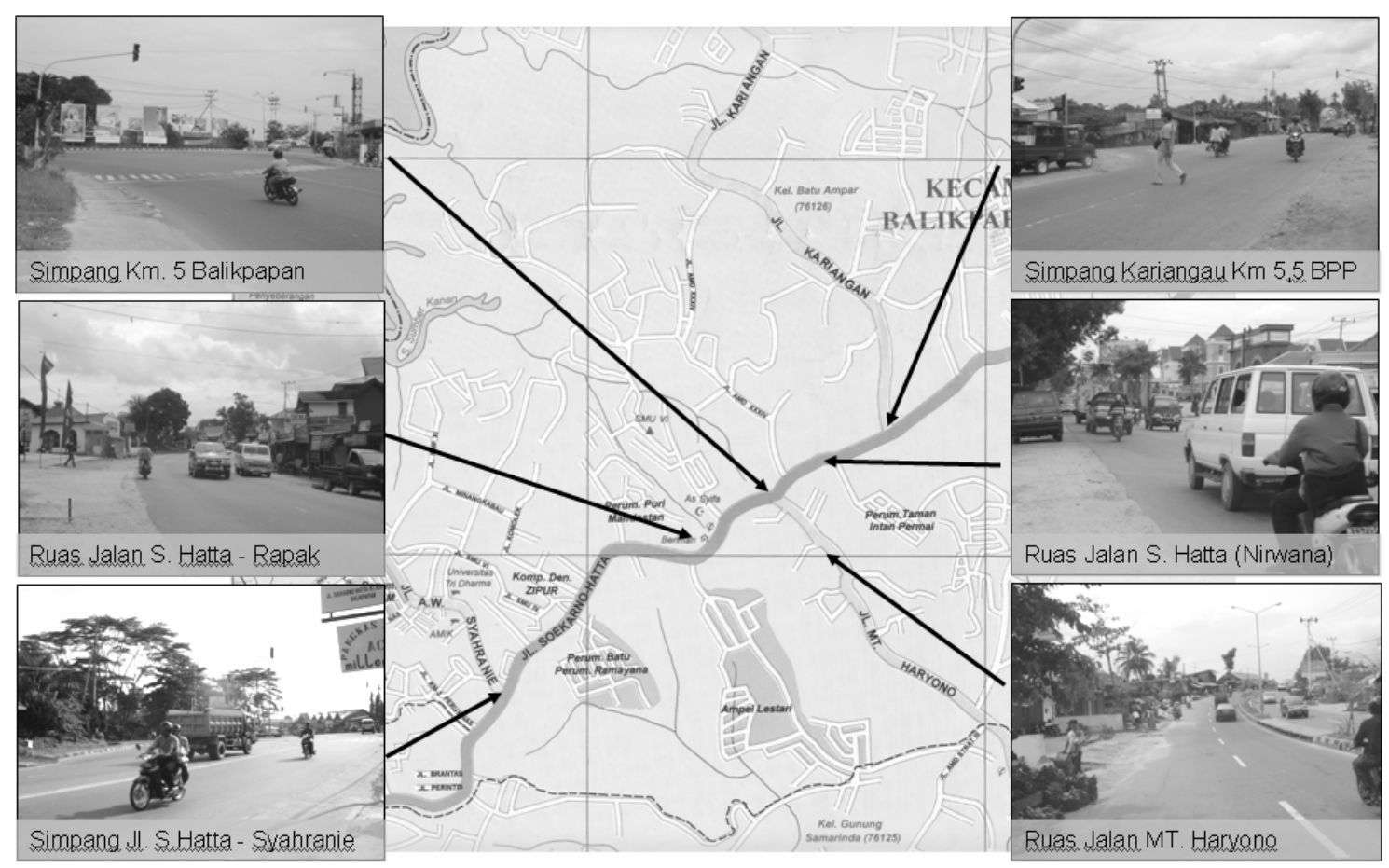

Gambar 2. Kondisi Jaringan Jalan dan Simpang Sekitar Simpang Kariangau

\subsection{Survei Pergerakan Lalu Lintas Simpang Kariangau (Intersection Traffic Count)}

Kegiatan yang dilakukan pada survei ini adalah menghitung pergerakan lalu lintas kendaraan pada masing-masing lengan simpang dengan klasifikasi kelas kendaraan sesuai dengan standar Bina Marga, yaitu :

1. Sepeda Motor/Scooter

2. Sedan, jeep, taksi, station wagon

3. Van/Combi (elf, colt, kijang, carry)

4. Pick up, mobil box kecil

5. Bus ukuran kecil, Mikrolet, Angkot

6. Bis ukuran besar (55 seat)

7. Truk ukuran sedang (2-as)

8. Truk ukuran besar (3-as atau lebih)

9. Truk Gandengan

10. Truk Peti-kemas (Container) 
Waktu pelaksanaan survei untuk simpang kariangau didasarkan pada waktu sibuk yang terjadi di simpang ini yang tergantung dari jam operasinya ferry penyeberangan di Kariangau yaitu pagi antara jam 07.00 - 10.00 dan sore hari jam 15.00 - 18.00 waktu setempat. Untuk orientasi arah pergerakan, sesuai dengan tiga lengan yang dimiliki simpang ini maka pergerakan lalu lintas dibagi menjadi tiga yaitu :

1. Pergerakan dari dan ke arah Jalan Kariangau

2. Pergerakan dari dan ke arah Samarinda

3. Pergerakan dari dan ke arah Balikpapan

Diagramatis simpang dan orientasi pergerakan lalu lintas dapat dilihat pada Gambar 3 dan untuk hasil survei pergerakan lalu lintas disimpang ini dapat dilihat pada Tabel 1 , Tabel 2, dan Tabel 3.

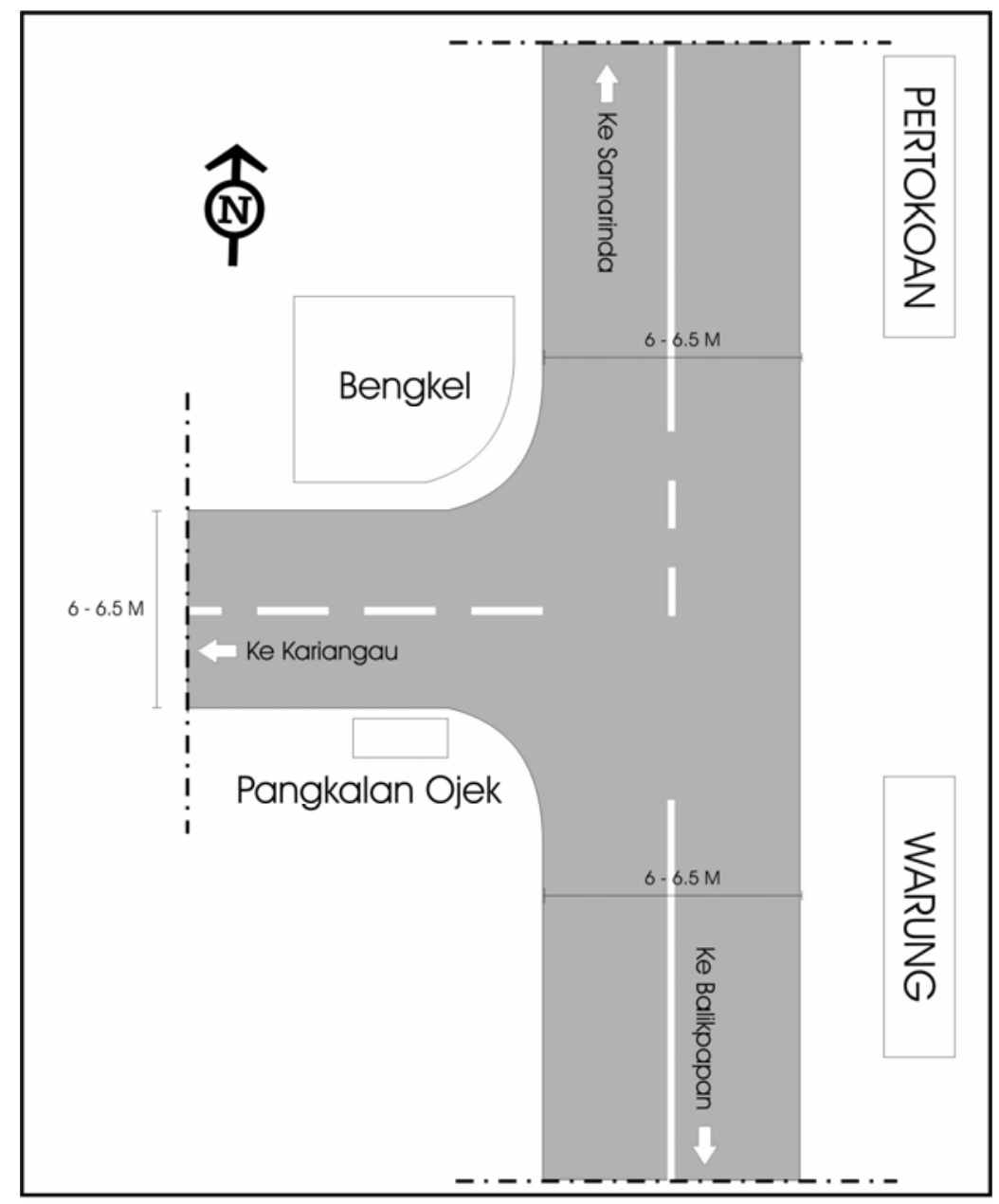

Gambar 3. Lay Out Geometris Simpang Kariangau Km 5,5 BPP Kota Balikpapan 

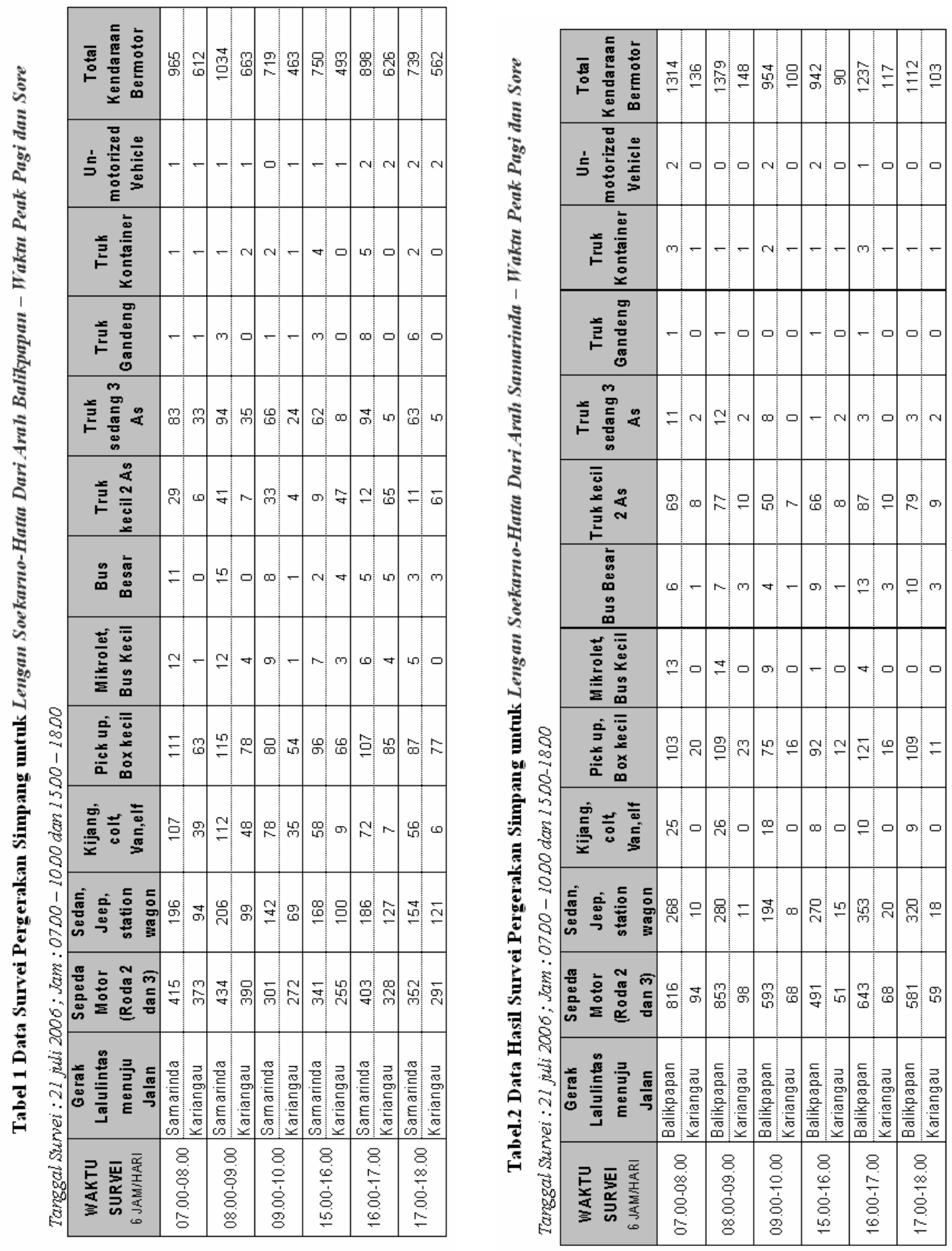


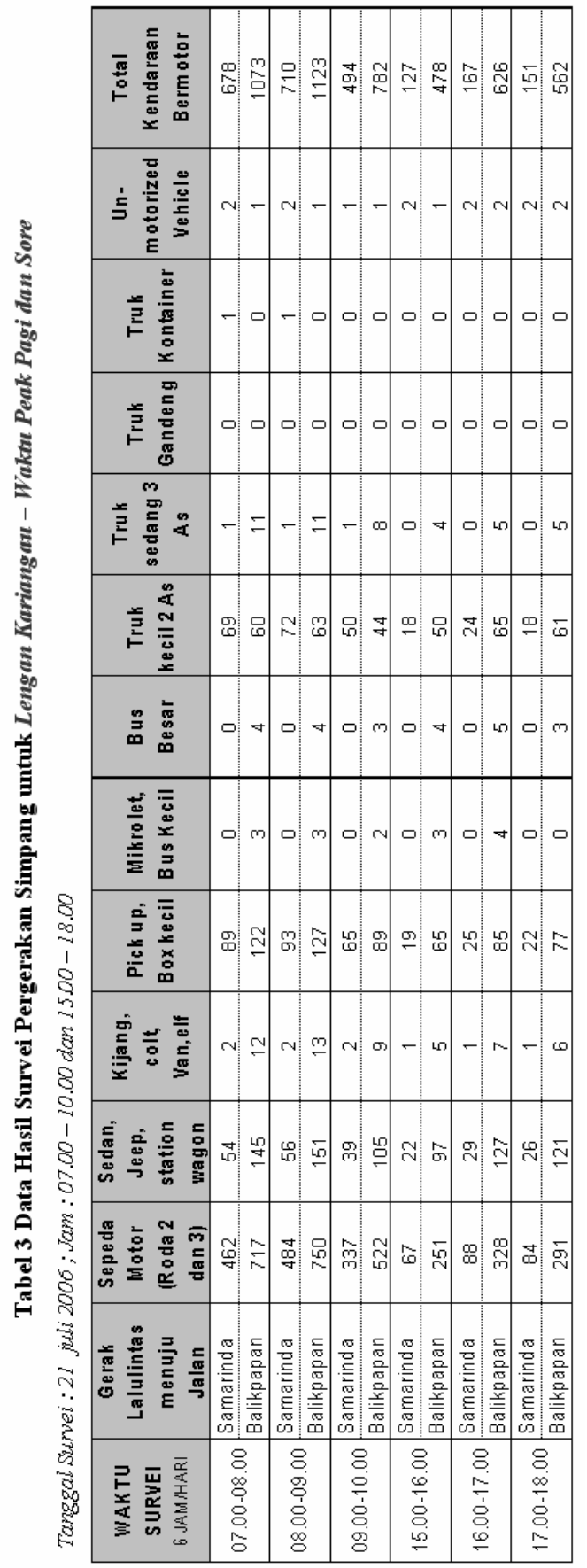

Alternatif Pemecahan Masalah Pada Simpang Tiga Kariangau-Soekarmo Hatta KM 5.5, 


\subsection{Survei Geometri Simpang Kariangau}

Dalam kegiatan survei Geometrik simpang kariangau, dilakukan pengukuran geometrik tiap lengan (approach) simpang serta pengamatan terhadap kondisi khusus yaitu kelandaian lengan kariangau yang sangat curam dan manuver pergerakan lalu lintas yang berpotensi menimbulkan masalah di persimpangan.

\section{Lengan Soekarno Hatta - dari arah Kota Balikpapan}

Pendekat simpang kariangau dari arah Kota Balikpapan memiliki tipe jalan 2/2 UD dengan lebar per lajur $3 \mathrm{~m}$ dan lebar bahu antara 2,5 - 3,5 meter. Bahu jalan tidak diperkeras (hanya tanah dan kerikil) dengan kondisi elevasi bahu dan lahan di sisi barat cenderung semakin menurun sedangkan sisi timur relatif datar kecuali dikomplek perumahan Bumi Nirwana yang terrain-nya menurun. Garis marka jalan di lengan ini sudah terhapus/ tidak jelas lagi dan lapisan atas perkerasan berdasarkan pengamatan visual diperkirakan telah mencapau batas aus lapisan. Jarak bangunan dari as jalan relatif jauh, sehingga untuk pengembangan ke depan masih sangat memungkinkan.

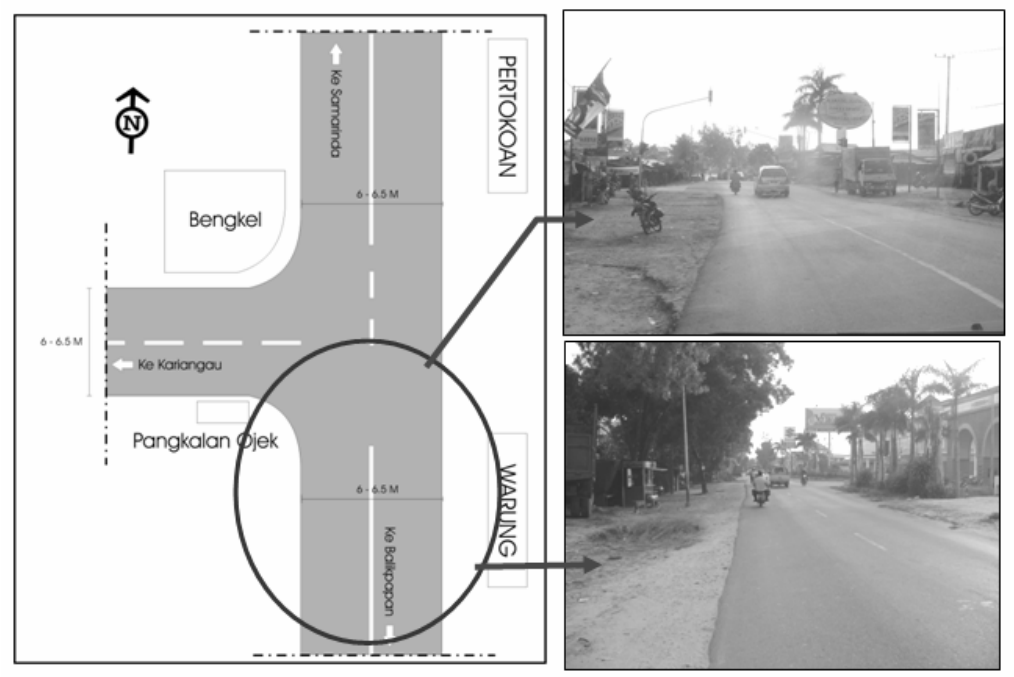

Gambar 4. Kondisi Geometri di Lengan

Jalan Soekarno-Hatta-Dari Arah Balikpapan

\section{Lengan Soekarno Hatta - dari arah Kota Samarinda}

Pendekat simpang kariangau dari arah Kota Samarinda merupakan kesatuan ruas dengan Lengan Soekarno Hatta - dari arah Balikpapan. Karena masih dalam ruas yang sama menjadikan penampang geometri kedua pendekat ini relatif sama. Hanya saja untuk bahu jalan mengalami penyempitan menjadi 1,5 - 3 meter. 


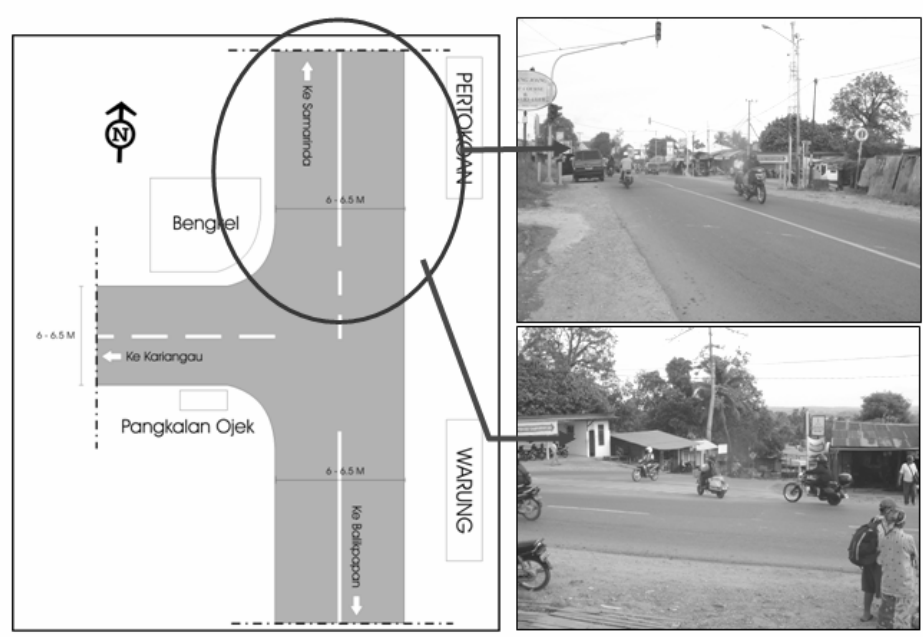

Gambar 5. Kondisi Geometri di Lengan

Jalan Soekarno-Hatta-Dari Arah Samarinda

\section{Lengan Kariangau}

Pendekat simpang kariangau dari arah Kariangau memiliki tipe jalan 2/2 UD dengan lebar per lajur 3 meter dan lebar bahu antara 1,5 - 3 meter. Sesaat sebelum memasuki mulut simpang, kendaraan yang berasal dari Kariangau akan melakukan pergerakan pendakian yang cukup terjal dengan kelandaian $>6 \%$. Kondisi geometris lengan kariangau dapat dilihat pada Gambar 6.

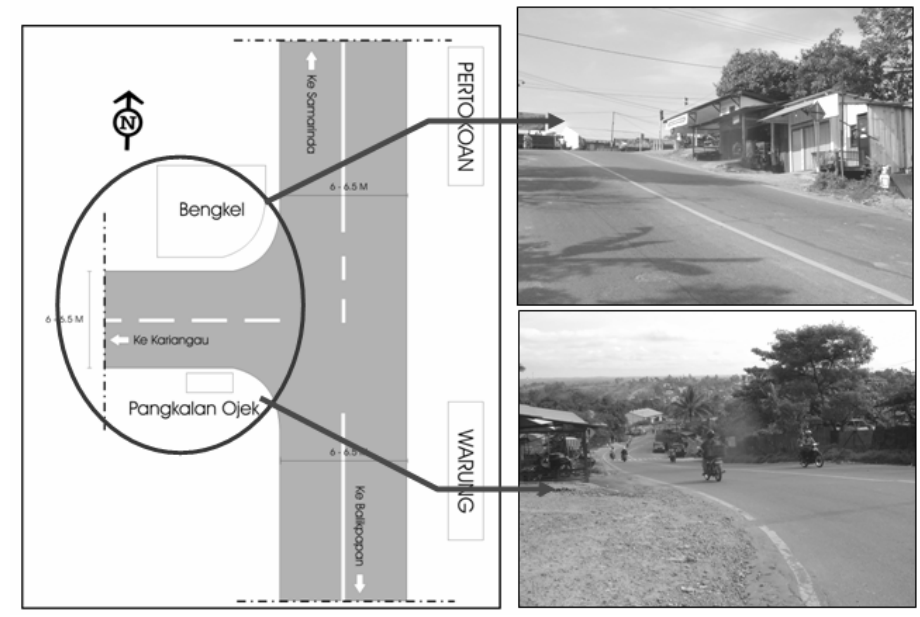

Gambar 6. Kondisi Geometri di Lengan Jalan Kariangau

\subsection{Pelaksanaan Survei Tata Guna Lahan Sekitar Simpang}

Dalam survei tata guna lahan sekitar simpang, dilakukan beberapa identifikasi pemanfaatan lahan samping di sekitar simpang dan pengamatan kecenderungan aktivitas penduduk disimpang ini. Pada ruas jalan soekarno Hatta umumnya tersebar 
warung/pertokoan milik warga. Dan \pm 100 meter dari mulut simpang ke arah selatan terdapat satu komplek perumahan Bumi Nirwana, dengan bangunan Ruko pada bagian depannya. Semakin ke selatan atau menuju arah Kota Balikpapan terutama via Rapak, aktivitas warga semakin ramai. Berbeda halnya bila ke utara atau ke arah Samarinda, bangunan semakin jarang dan aktivitas warga yang ramai hanya bersifat spot saja. Untuk arah jalan Kariangau, pemanfaatan lahan baik sebagai pemukiman maupun pertokoan masih sangat jarang. Masih terdapat banyak lahan tidur yang belum dimanfaatkan secara optimal. Sehingga semakin ke Barat menuju arah Penyebrangan Kariangau, aktivitas warga cenderung sepi dan akan ramai lagi sesaat sebelum memasuki pelabuhan.

\section{ANALISIS DATA SURVEI}

\subsection{Analisis Survei Jaringan Jalan}

Dari hasil survei jaringan jalan yang telah dilakukan sebelumnya, diketahui bahwa di sekitar simpang terdapat beberapa titik simpul pertemuan ruas jalan yang lokasinya cukup berdekatan. Titik simpul pertemuan ruas jalan (simpang) tersebut antara lain :

1. Simpang Jalan Soekarno Hatta Km.5

2. Simpang Rapak (Terminal)

3. Simpang A.H Syahranie

Ketiga simpang tersebut diatas adalah simpang tiga, dua simpang pertama yaitu simpang Jalan Soekarno-Hatta Km.5 dan Simpang Rapak (Terminal) memiliki lampu pengaturan lalu lintas namun tidak diaktifkan, sedangkan untuk simpang A.H Syahranie meski tidak memiliki lampu lalu lintas namun telah diatur dengan pulau pengarah pergerakan (island) dan dipasangi yellow amber. Simpang yang paling dekat dengan simpang Kariangau adalah simpang jalan Soekarno-Hatta Km. 5 dengan jarak antar mulut simpang adalah $\pm 500 \mathrm{~m}$. Pada ruas antar kedua simpang ini tidak jarang mengalami kemacetan terutama pada saat-saat jam sibuk. Oleh sebab itu, diperlukan suatu sistem pengaturan kedua simpang yang saling berinteraksi dan terintegrasi baik melalui manajemen waktu siklus lampu lalu lintas maupun sistem pengaturan lainnya yang perlu dikaji secara khusus.

Untuk simpang-simpang kecil (gang) seperti akses menuju komplek perumahan berdasarkan kondisi dilapangan dianggap tidak menimbulkan pengaruh yang cukup besar terhadap kelancaran arus lalu lintas. Sehingga untuk kondisi jaringan jalan yang ada disekitar simpang, secara umum masih cukup baik kecuali masalah interaksi sistem pengaturan simpang di Km.5 dengan simpang Kariangau. 


\subsection{Analisis Data Survey Pergerakan Simpang}

Setelah melakukan survei pergerakan kendaraan di simpang Kariangau selama 2 hari, selanjutnya dilakukan inputing dan pengolahan data hingga analisisnya. Dari data faktual yang didapat, diketahui bahwa pola pergerakan yang terjadi disimpang ini selama 2 hari berturut-turut relatif sama. Kondisi jam puncak yang telah diprediksi sebelumnya pun ternyata sesuai dengan keadaan dilapangan. Untuk kondisi pergerakan masing-masing simpang dari hasil survei pergerakan simpang ini dapat dideskripsikan seperti pada Tabel 4.

Tabel 4. Pergerakan Kendaraan rata-rata pada masing-masing lengan simpang Kariangau

\begin{tabular}{|c|c|c|c|c|}
\hline \multirow{2}{*}{ Lengan yang Diamati } & $\begin{array}{c}\text { Arah Pergerakan } \\
\text { Lalu Lintas }\end{array}$ & Kend/6 Jam & Smp/6jam & Split P ortion \\
\hline \multirow{2}{*}{ S.Hatta - Balikpapan } & Samarinda & 4717 & 1721 & $60 \%$ \\
\cline { 2 - 5 } & Kariangau & 3131 & 1342 & $40 \%$ \\
\hline \multirow{2}{*}{ S.Hatta - Samarinda } & Balikpapan & 6017 & 2033 & $91 \%$ \\
\cline { 2 - 5 } & Kariangau & 601 & 443 & $33 \%$ \\
\hline \multirow{2}{*}{ Kariangau } & Samarinda & 2103 & 917 & $67 \%$ \\
\hline
\end{tabular}

\section{DESAIN DAN GAMBAR DESAIN}

\subsection{Desain Geometrik Simpang}

Dalam meningkatkan kinerja simpang kariangau, salah satu metode yang akan di gunakan adalah dengan melakukan rekayasa geometrik simpang. Oleh karena itu, penulis menyusun beberapa alternatif pemecahan masalah persimpangan yang ditinjau dari sisi kondisi gemetriknya. Beberapa pemecahan yang diusulkan diantaranya adalah sebagai berikut :

2. Alternatif $1:$ (Rekayasa Geometrik Lajur)

- Pembuatan lajur khusus (lajur baru) untuk pergerakan kendaraan dari arah Samarinda menuju Balikpapan yang terpisah dengan lajur yang menuju kariangau. Alternatif ini bertujuan agar kendaraan yang dari arah Samarinda sesaat sebelum memasuki simpang terlebih dahulu diarahkan masuk ke lajur khusus sebagai lajur perlambatan dan saat mencapai jarak aman baru diarahkan 
kembali bergabung (merging) dengan kendaraan yang berasal dari kariangau seperti yang terlihat pada Gambar 8.

- Untuk arah dari Balikpapan menuju Samarinda yang sebenarnya memang tidak dapat menghindari crossing conflict dengan kendaraan dari Kariangau yang menuju ke Balikpapan, pemecahannya dengan memasang beberapa rambu-rambu peringatan sebelum memasuki simpang yang diantaranya bertuliskan :

1. Dahulukan Kendaraan dari arah Kariangau

2. Hati-Hati Simpang Rawan Kecelakaan

3. Kurangi Kecepatan Anda Sekarang Juga

- Memasang Speed Trap (Marka kejut) di lengan arah dari Balikpapan dan dari Samarinda untuk memberi peringatan sekaligus mengarahkan pengemudi agar mengurangi kecepatan kendaraannya sesaat sebelum memasuki simpang.

- Melakukan overlay dan pengecatan ulang marka-marka jalan terutama yang ada di sekitar simpang

2. Alternatif 2 : (Perbaikan Alinyemen, dapat dikombinasikan dengan Alternatif 1)

1 Mengurangi Kecuraman lengan kariangau dengan merekonstruksi lajur pendakian.

2 Merekonstruksi alinyemen vertikal lajur-lajur pendekat.

Kedua alternatif diatas selanjutnya akan di kaji lebih lanjut dari segi perencanaan teknis dalam desain geometrik simpang dan desain pengaturan simpang beserta gambargambar usulan penanganan simpang pada bab selanjutnya.

\subsection{Desain Pengaturan Simpang}

Permasalahan lalu lintas yang terjadi dipersimpangan muncul karena adanya titiktitik konflik antar pergerakan kendaraan. Titik-titik konflik yang timbul pada simpang bervariasi menurut jenis manuvernya. Jumlah dari potensi titik-titik konflik pada simpang tergantung dari :

1. Jumlah kaki simpang

2. Jumlah lajur dari setiap kaki simpang

3. Jumlah pengaturan simpang

4. Jumlah arah pergerakan

Ada dua tipe konflik, yaitu : primer dan sekunder. Konflik primer termasuk konflik antara arus lalu-lintas dari arah tegak lurus. Konflik sekunder termasuk konflik antara arus 
lalu-lintas belok kanan dan lalu-lintas arah lainnya atau antara arus belok kiri dan pejalan kaki.

Sinyal lalu-lintas terutama menghilangkan konflik primer dan mungkin juga konflik sekunder. Bila tidak ada konflik (primer dan sekunder) maka pergerakan-pergerakan adalah tak terganggu. Bila masih ada konflik sekunder, pergerakan tetap akan terganggu

Tujuan utama dari pengaturan lalu lintas umumnya adalah untuk menjaga keselamatan arus lalu lintas dengan memberikan petunjuk-petunjuk yang jelas dan terarah, tidak menimbulkan keraguan. Untuk pengaturan lalu lintas simpang kariangau akan di desain dengan dua metode yaitu pengaturan lalu lintas simpang tanpa sinyal (marka, rambu, dan pulau-pulau lalu lintas) dan pengaturan simpang dengan sinyal (lampu lalu lintas). Pemilihan jenis pengaturan simpang ini didasarkan pada karakteristik fisik dari simpang maupun kondisi lalu lintasnya.

Perencanaan kedua metode pengaturan simpang tersebut akan dideskripsikan sebagai berikut :

\section{Pengaturan Simpang tanpa sinyal (Unsignalized Intersection)}

Saat ini kondisi simpang kariangau dianggap simpang tak bersinyal karena meskipun terdapat lampu lalu lintas namun tidak diaktifkan karena tidak mampu mengatasi permasalahan yang ada disimpang saat ini. Untuk selanjutnya, metode pengaturan simpang yang direkomendasikan meliputi teknik-teknik berikut:

\section{- Aturan prioritas}

Persimpangan dengan prioritas adalah merupakan kontrol yang paling umum. ROW pada persimpangan dengan prioritas harus terlihat dengan jelas, baik marka dan rambu jalan. Secara umum, jalan utama mempunyai ROW. Jika volume besar pada jalan yang lebih kecil atau jika jalan utama tidak lurus, aspek efisiensi dan keselamatan memerlukan pertimbangan tertentu.

Ketentuan dari aturan prioritas pada simpang tanpa sinyal lalu-lintas sangat mempengaruhi kelancaran pergerakan arus lalu-lintas yang saling berpotongan. Terutama pada simpang yang merupakan perpotongan dari ruas-ruas jalan yang mempunyai kelas yang sama.

Untuk simpang kariangau, aturan prioritas di kenakan pada lengan yang dianggap manuvernya sulit dan rawan yaitu lengan kariangau dengan manuver daki yang sangat curam/terjal dan panjang. Sehingga, meskipun untuk aturan prioritas sebenarnya lengan Jalan Soekarno-Hatta yang lebih berhak, namun karena tingkat kesulitan manuver 
kendaraan yang cukup tinggi untuk kendaraan dari kariangau, maka pergerakan kendaraan dari lengan ini akan lebih di prioritaskan.

- Rambu dan/atau marka, misalnya : yield signs, stop signs, channelization Yield signs

Pengaturan ini digunakan untuk melindungi arus lalu-lintas dari salah satu ruas jalan pada dua ruas jalan yang saling berpotongan tanpa harus berhenti sama sekali. Sehingga pengendara tidak terlalu terhambat bila dibandingkan dengan pengaturan stop signs.

\section{Stop signs}

Pengaturan simpang dengan stop signs digunakan bila pengendara pada kaki simpang harus berhenti secara penuh sebelum memasuki simpang. Pengaturan ini digunakan pada pertemuan antara minor road dengan major road.

\section{Channelization}

Pengaturan simpang dengan channelization terutama untuk memisahkan lajur lalu-lintas menerus dan lajur belok. Bentuk fisiknya dapat berupa marka atau pulaupulau lalu-lintas. Dengan pengaturan ini arah pergerakan lalu-lintas lebih dipertegas sehingga kendaraan dapat dengan mudah dan aman memasuki simpang sesuai pada lajurnya.

\section{- Penambahan lajur}

Penambahan jumlah lajur pada persimpangan selain akan meningkatkan kapasitas juga berguna sebagai teknik pengaturan lajur dengan pembagian sesuai arah pergerakan. Pada simpang kariangau, direkomendasikan adanya penambahan lajur untuk pergerakan kendaraan yang berasal dari Samarinda. Lajur baru ini akan digunakan untuk pergerakan menerus dari arah Samarinda menuju Balikpapan, sehingga akan terjadi pemisahan lajur antara kendaraan yang ke Balikpapan dengan kendaraan yang akan menuju kariangau.

Bagian lain yang perlu ditambahkan lajur lalu lintas adalah pergerakan kendaraan dari arah lengan kariangau yang berbelok ke arah Samarinda. Hal ini dilakukan untuk mengurangi merging conflict dengan kendaraan yang berasal dari Balikpapan menuju ke arah Samarinda.

Untuk saat ini, direkomendasikan pengaturan simpang di kariangau tanpa sinyal dengan mengkombinasikan teknik-teknik diatas yang disesuaikan dengan kondisi dilapangan. Desain pengaturan yang dibuat haruslah efisien dan efektif serta mampu 
meningkatkan kinerja simpang yang ada saat ini. Gambar desain pengaturan simpang yang direkomendasikan dapat dilihat pada gambar 8.

\section{Pengaturan Simpang dengan Sinyal Lampu lalu-lintas}

Sebenarnya untuk pengaturan simpang dengan sinyal lalu-lintas termasuk yang paling efektif terutama untuk volume lalu-lintas pada kaki-kaki simpang yang relatif tinggi. Pengaturan ini dapat mengurangi atau menghilangkan titik-titik konflik pada simpang dengan memisahkan pergerakan arus lalu-lintas pada waktu yang berbeda-beda.

Peralihan antara persimpangan dengan prioritas menjadi lampu lalu-lintas biasanya di-justifikasi dengan pengurangan pada keterlambatan dan kecelakaan, hal utama yang menentukan peralihan ke lampu lalu-lintas ditentukan berdasarkan arus lalu-lintas. Lampu lalu-lintas adalah hal yang paling efektif jika volume turning movement rendah, dan jumlah stage sedikit.

Simpang Kariangau sebelumnya telah memiliki sistem pengaturan dengan lampu lalu lintas. Namun ternyata lampu ini tidak mampu mengatur lalu lintas yang ada. Masalahnya bukan terjadi pada tingginya volume kendaraan yang masuk simpang, akan tetapi keberadaan lampu ini tidak mampu mengakomodir kebutuhan pengendara dari arah lengan kariangau yang mengalami kesulitan bermanuver naik untuk memasuki dan melewati simpang kariangau. Sehingga perlu adanya kajian lengan mana yang diprioritaskan serta menjajagi kemungkinan penggunaan teknik pengaturan sinyal ini yang dikombinasikan dengan teknik pengaturan simpang yang didesain tanpa sinyal. Namun, jika problem kapasitas terjadi pada lampu lalu-lintas, beberapa parameter berikut diperlukan untuk meningkatkan kapasitas :

1. Menghitung kembali waktu siklus optimum.

2. Mereview pengaturan fase optimum.

3. Menentukan pengaturan optimum untuk arus pejalan kaki.

4. Meningkatkan kapasitas jalur approach dan exit, dan menyediakan jalur turning movement.

\subsection{Gambar Desain Simpang}

Gambar desain simpang ini merupakan hasil rekayasa geometrik penanganan simpang yang di usulkan dalam rangka meningkatan kinerja simpang kariangau. Desain geometrik ini bertujuan mengatur konflik-konflik primer maupun sekunder yang menjadi penyebab tingginya tingkat kecelakaan yang terjadi di simpang kariangau. 


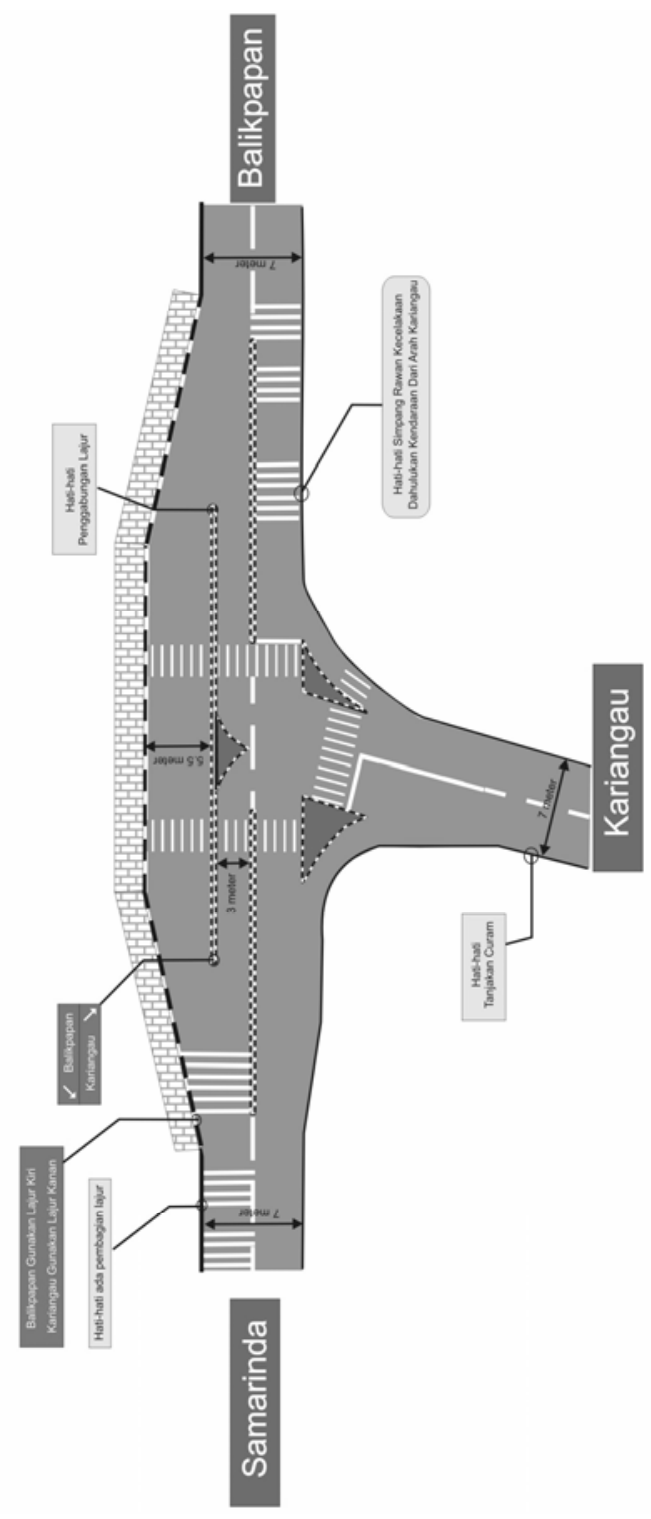

Gambar 8. Desain Simpang Kariangau dengan Rekayasa Geometrik

\section{KESIMPULAN DAN SARAN}

\subsection{Kesimpulan}

Alternatif pemecahan masalah persimpangan seoptimal mungkin disesuaikan dengan kondisi faktual yang terjadi dilapangan. Simpang Kariangau Balikpapan memiliki masalah geometrik pada salah satu lengannya dimana lengan tersebut memiliki kelandaian yang curam sehingga menyulitkan kendaraan untuk bermanuver dari lengan ini termasuk menghindari konflik dengan kendaraan dari lengan yang lain. Solusi yang dianggap terbaik untuk saat ini adalah melakukan pengaturan tanpa sinyal melalui rekayasa geometrik dengan 
penambahan lajur, pembuatan speed trap, pembuatan pulau/separator, dan pengaturan taper. Pengaturan pergerakan kendaraan dengan pembuatan lajur menerus dan speed trap diharapkan mampu meredam laju kendaraan dari masing-masing lengan sehingga mampu memperkecil resiko konflik atau benturan saat melakukan proses merging antar kendaraan, sedangkan taper diharapkan akan memperlancar pergerakan kendaraan yang belok kiri sehingga tidak mengganggu pergerakan kendaraan menerus dan belok kanan. Dengan metode diatas diharapkan tingkat pelayanan simpang kariangau dapat lebih baik lagi dan mampu menurunkan tingginya potensi kecelakaan yang terjadi selama ini sehingga faktor keselamatan pengguna jalan pada simpang ini dapat lebih ditingkatkan.

\subsection{Saran}

Perlu untuk mengkaji kinerja simpang lebih lanjut dengan melakukan rekayasa alinyemen vertikal terutama pada lengan dari arah Kariangau dengan memperbaiki grade lajur daki kendaraan pada saat memasuki simpang.

\section{PUSTAKA}

1. Media Tehnik Consultant, CV (2006), Laporan Akhir Studi Peningkatan Kinerja Simpang Kariangau Km 5,5 Kota Balikpapan, subdin Bina Marga, Balikpapan.

2. Susilo, B.H. (1993), Survei dan Karakteristik Lalu Lintas, Diktat Kuliah Jurusan Teknik Sipil Universitas Kristen Maranatha, Bandung.

[1] Disampaikan dalam Simposium IX Forum Studi Transportasi Antar Perguruan Tinggi (FSTPT), Universitas Brawijaya - Malang, 17 - 18 November 2006

[2] Budi Hartanto S., Dosen Tetap Jurusan Teknik Sipil, Universitas Kristen Maranatha, Bandung.

[3] Apriyanto Loentan, Alumnus Jurusan Teknik Sipil, Universitas Kristen Maranatha, Bandung 